\title{
DPP-4 Inhibition Ameliorates Pancreatic $\beta$-Cell Failure and Improves Glucose Tolerance in the Mouse Model of Wolfram Syndrome
}

\author{
Yasuhiro Tanji ${ }^{1}$, Suguru Yamaguchi1,2, Yasushi Ishigaki', Hideki Katagiri'1, \\ Yoshitomo Oka', Hisamitsu Ishihara ${ }^{2 *}$ \\ ${ }^{1}$ Division of Molecular Metabolism and Diabetes, Tohoku University Graduate School of Medicine, Sendai, \\ Japan \\ ${ }^{2}$ Division of Diabetes and Metabolic Diseases, Nihon University School of Medicine, Tokyo, Japan \\ Email: ${ }^{*}$ ishihara.hisamitsu@nihon-u.ac.jp
}

Received 17 February 2015; accepted 28 April 2015; published 4 May 2015

Copyright (C) 2015 by authors and Scientific Research Publishing Inc.

This work is licensed under the Creative Commons Attribution International License (CC BY). http://creativecommons.org/licenses/by/4.0/

(c) (i) Open Access

\begin{abstract}
Wolfram syndrome, an autosomal recessive disorder associated with diabetes and optic atrophy, is caused by mutations in the WFS1 gene encoding wolframin, an endoplasmic reticulum membrane protein. Recent development of incretin-based drugs demonstrates promising outcomes for treatment of diabetes mellitus. The aim of this study is to evaluate whether dipeptidyl peptidase-4 inhibition is effective for treating endoplasmic reticulum stress-mediated $\beta$-dell failure and impaired glucose tolerance in WFS1-deficient mice $\left(W f s 1^{-/-}\right) . W f s 1^{-/-}$mice were orally administrated with vildagliptin (50 mg/kg), a dipeptidyl peptidase-4 inhibitor, twice a day for 4 weeks. The pancreases of these mice were subjected to morphological and biochemical analyses and their glucose tolerance was studied. Electron microscopic studies revealed that vildagliptin reduced number of $\beta$-cell containing swollen endoplasmic reticulum in $W f 1^{-/-}$mice. Vildagliptin treatment increased pancreatic insulin content by $30 \%$ in $W f 1^{-/-}$mice. Oral and intraperitoneal glucose tolerance tests showed improved glucose tolerance in vildagliptin-treated $W f s 1^{-/-}$mice with increased glucose responsiveness of insulin secretion as compared with vehicle-treated mutant mice. These effects by dipeptidyl peptidase-4 inhibition were partly prevented by glucagon-like peptide-1 receptor blockade. These findings provide evidence that activation of the incretin system by dipeptidyl peptidase- 4 inhibition plays a protective role against $\beta$-cell failure in wolframin-deficiency. Our data suggest that diabetes in patients affected with Wolfram syndrome could be treated by incretin-based drugs. Furthermore, since WFS1 dysfunction could be involved in common forms of
\end{abstract}

${ }^{*}$ Corresponding author.

How to cite this paper: Tanji, Y., Yamaguchi, S., Ishigaki, Y., Katagiri, H., Oka, Y. and Ishihara, H. (2015) DPP-4 Inhibition Ameliorates Pancreatic B-Cell Failure and Improves Glucose Tolerance in the Mouse Model of Wolfram Syndrome. Journal of Diabetes Mellitus, 5, 72-80. http://dx.doi.org/10.4236/jdm.2015.52009 
type 2 diabetes mellitus, our results strengthen the mechanistic rational of using this drug for the disease.

\title{
Keywords
}

\author{
Diabetes, Incretin, Endoplasmic Reticulum Stress, WFS1, Wolframin
}

\section{Introduction}

Wolfram syndrome is a rare autosomal recessive disorder characterized by juvenile-onset diabetes mellitus, optic atrophy, diabetes insipidus and sensorineural deafness [1]. This syndrome is caused by mutations in the WFS1 gene, which encodes wolframin, an endoplasmic reticulum (ER) resident membrane protein [2] [3]. Interestingly, recent studies indicated sequence variants in this gene confer risk of type 2 diabetes [4] [5]. We have generated Wfs1 knock-out mice which develop impaired glucose homeostasis due to progressive $\beta$-cell loss [6]. The $\beta$-cell failure in wolframin-deficiency was then revealed to result from increased ER stress [7].

ER stress is triggered when the amount of unfolded and misfolded proteins exceeds the folding capacity of the ER. To cope with this stress, cells activate intracellular signaling pathways, termed the unfolded protein response [8]. However, when ER stress extensively impairs ER homeostasis, the apoptotic pathways are triggered, leading to cell death. Recent studies revealed that one of the causes of $\beta$-cell loss in diabetes is ERstress-mediated apoptosis [9].

Incretin hormones, glucagon-like peptide-1(GLP-1) and glucose-dependent insulinotropic peptide (GIP), stimulate insulin secretion in a glucose-dependent manner. Activation of GLP-1 receptors [10]-[12] or GIP receptors [13] has also been shown to maintain and/or increase $\beta$-cell mass. In the blood stream, GLP- 1 and GIP are immediately degraded by dipeptidyl peptidase 4 (DPP-4). To raise circulating levels of active incretins, DPP-4 inhibitors are clinically used as a novel strategy for treating diabetes. It has recently been shown that DPP-4 inhibitor vildagliptin ameliorates ER stress in $\beta$-cells of a mouse model of diabetes [14]. Here, we examined whether DPP-4 inhibition is beneficial for diabetes in Wolfram syndrome, using a mouse model of the disease.

\section{Materials and Methods}

\subsection{Animals}

All animal experiments were approved by Tohoku University Institutional Animal Care and Use Committee. $W f \mathrm{S1}^{-/-}$mice and their wild-type littermates had a C57BL/6 background and were described previously [6]. Only male mice were studied. All mice were housed one mouse per cage under a light/dark cycle of 12 hours. Either vildagliptin (Novartis pharma AG Switzerland, $50 \mathrm{mg} / \mathrm{kg}$ body weight) or vehicle (water) was orally administrated twice a day (at 9:00 A.M. and 7:00 P.M.) at a volume of $10 \mathrm{~mL} / \mathrm{kg}$. In some experiments, $W f \mathrm{~s}^{-/-}$mice wereintraperitoneally injected with either exendin ( 9 - 39) (30 nmol/body weight) or saline 45 min before treatment with vildagliptin or vehicle.

\subsection{Physiological Studies}

Food intake and body weight were measured twice a week. Blood samples were collected from the tail vein. Blood glucose was measured using a Glutest glucose sensor device (Sanwa Kagaku Kenkyusho, Nagoya, Japan) which monitors electric current generated through glucose oxidation to gluconic acid by glucose oxidase. Serum insulin levels were determined using an insulin ELISA kit (Morinaga Institute of Biological Science, Tokyo, Japan). For analysis of active GLP-1, mice were administered with $20 \%$ glucose solution ( $2 \mathrm{~g} / \mathrm{kg}$ body weight), and 15 min later, mice were killed and blood was collected into tubes containing a DPP-4 inhibitor (Millipore Billerica, MA), and analyzed using an active GLP-1 (7 - 36) ELISA kit (Linco Research Inc., St Charles, MO). For an oral glucose tolerance test (OGTT) and intraperitoneal glucose tolerance test (IPGTT), animals after 16 hour-fast were administered with $20 \%$ glucose solution ( $2 \mathrm{~g} / \mathrm{kg}$ body weight). Laboratory technicians have performed analyses kept blind to treatment allocation by numbering the sample tubes serially. Glucose tolerancetests have been performed by technicians with mouse genotypes being kept blind. 


\subsection{Pancreas Insulin Content}

Pancreases were excised and minced by scissors in acid ethanol, and left at $-20^{\circ} \mathrm{C}$ for 48 hours, with sonication every 24 hours. Insulin concentrations in the acid ethanol were determined with an insulin ELISA Kit (Morinaga).

\subsection{Transmission Electron Microscopy}

The samples of pancreases were fixed with $2 \%$ glutaraldehyde plus $2 \%$ paraformaldehyde in $0.1 \mathrm{M}$ phosphate buffer (PB, pH 7.4) at $4^{\circ} \mathrm{C}$, and subsequently post-fixed with $2 \%$ osmium tetroxide in $0.1 \mathrm{M} \mathrm{PB}$ at $4^{\circ} \mathrm{C}$ for 2hours. Then, the specimens were dehydrated in agraded ethanol, replaced in propyleneoxide, and embedded in the epoxy resin. Ultrathin sections were obtained by ultramicrotomy technique. Ultrathin sections stained with uranyl acetate at $60^{\circ} \mathrm{C}$ for 20 minutes and modified Sato's lead solution for 5 minutes were submitted to Transmission Electron Microscope observation (JEM-1200EX, JEOL). Electron microghraphs of $\beta$-cells were randomly selected and examined in a masked manner. A $\beta$-cell with significantly swollen ER visible at $6600 \times$ magnification (at least $50 \mathrm{~nm}$ in width) is counted for a positive $\beta$-cell with swollen ER.

\subsection{Statistical Analysis}

Data are presented as means \pm SE. Differences between groups were assessed by Student's t test. P $<0.05$ was considered significant.

\section{Results}

\subsection{A Single Dose of Vildagliptin Enhanced $\beta$-Cell Responsiveness in Wfs $1^{-/-}$Mice}

In order to determine whether acute effects of vildagliptin are preserved in WFS1-deficient mice, an oral glucose tolerance test (OGTT) was performed after a single administration of the drug into male wild-type (WT) and $W f s 1^{-/-}$mice. We used mice at 5 weeks of age when $W f s 1^{-/}$mice on the C57BL/6 background show no apparent increases in blood glucose levels [6]. The mice were fasted overnight, and vildagliptin (50 mg/kg) was given through gastric tubes. Forty five minutes after vildagliptin administration, an OGTT was started. Plasma levels of active GLP-1, one of main DPP-4 targets, measured 15 minutes after glucose loading, were increased in $W f s 1^{-/}$mice as in WT mice by a single dose of vildagliptin (Figure 1(a)). Vildagliptin reduced glycemic excursion in both WT and $W f s 1^{-/-}$mice (Figure 1(b)). The plasma insulin over glucose levels at 15 min after glucose load were significantly elevated, indicating that $\beta$-cell responsiveness was increased by the prior treatment with vildagliptin in both strains (Figure $1(\mathrm{c})$ ). These data suggested that principle mechanisms of a DPP-4 inhibitor are preserved in the wolframin-deficient mice.

\subsection{Four-Week Treatment with Vildagliptin Ameliorated $\beta$-Cell Failure in $W f s^{1-/-}$ Mice}

To investigate effects of continuous administration of vildagliptinon $\beta$-cell failure and impaired glucose tolerance in $W f s 1^{--}$mice, vildagliptin $(50 \mathrm{mg} / \mathrm{kg}$ ) was orally administrated twice a day for 4 weeks, starting at 5 weeks of age. There was no difference in body weight throughout the study between vehicle- and vildagliptinadministrated mice of both strains (data not shown). The average daily food intake also showed no differences among four groups (data not shown). Similar blood glucose levels measured in non-fasted states were observed among four groups during 4-week administration period (data not shown).

Since we showed that $\beta$-cell failure in $W f s 1^{-/-}$mice results from increased ER stress [7] and recent data indicated DPP-4 inhibition ameliorates ER stress in the $\beta$-cell [14], we had expected that $\beta$-cell ER stress might be improved in WFS1-deficient mice treated with vildagliptin. To investigate this possibility, ER morphology was analyzed by electron microscopic method in these mice. Consistent with the fact that wolframin-deficient $\beta$-cells are suffered from ER stress, $\beta$-cells with swollen ER, a typical phenotype of ER-stressed $\beta$-cells [15], was frequently observed in $W f s 1^{-1-}$ mice (Figure 2(a)). Vildagliptin treatment for 4 weeks resulted in reduction in cell numbers with swollen ER, indicating that enhancement of incretin action reduced ER stress in wolframin-deficient $\beta$-cells.

After 4-week administration of vildagliptin, dagliptin, we evaluated pancreatic insulin content of these mice. Pancreatic insulin content of vehicle-treated $W f s 1^{-/}$mice at 9 weeks of age was decreased to $47 \pm 5 \%$ (p $<0.01$ ) 


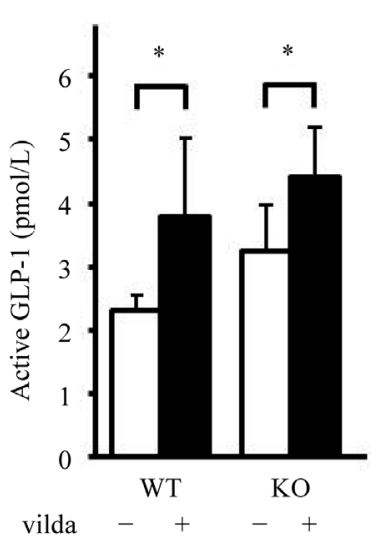

(a)

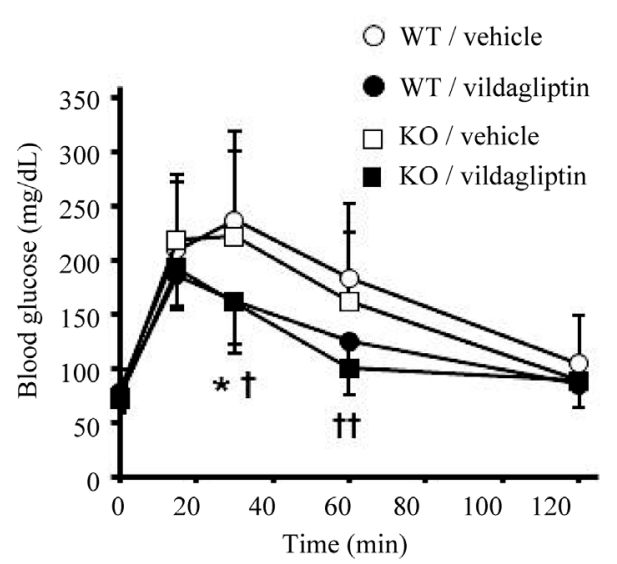

(b)

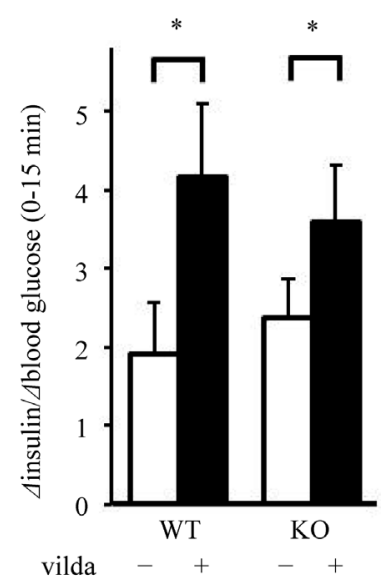

(c)

Figure 1. Oral glucose tolerance tests ( $2 \mathrm{~g} / \mathrm{kg}$ body weight) were performed $45 \mathrm{~min}$ after a single treatment of vildagliptin vehicle, in male WT mice and $W f s 1^{-/}$mice (KO) at 5 weeks of age. (a) Active GLP-1 levels were measured at 15 min after glucose load. ${ }^{*} \mathrm{p}<0.05$. (b) Blood glucose levels were lower in vildagliptin-treated mice. ${ }^{*} \mathrm{p}<0.05$ between vildagliptin- and vehicle-treated WT mice. ${ }^{\dagger} \mathrm{p}<0.05$ between vildagliptin- and vehicle-treated $W f s 1^{-/-}$mice. ${ }^{\dagger \dagger} \mathrm{p}<0.01$ between vildagliptinand vehicle-treated $W f s 1^{-/-}$mice. (c) Insulin secretory response was calculated by dividing changes of plasma insulin levels during 15 min by changes of blood glucose. ${ }^{*} \mathrm{p}<0.05$. Data are presented as means $\pm \mathrm{SE}, \mathrm{n}=7-12$ mice.

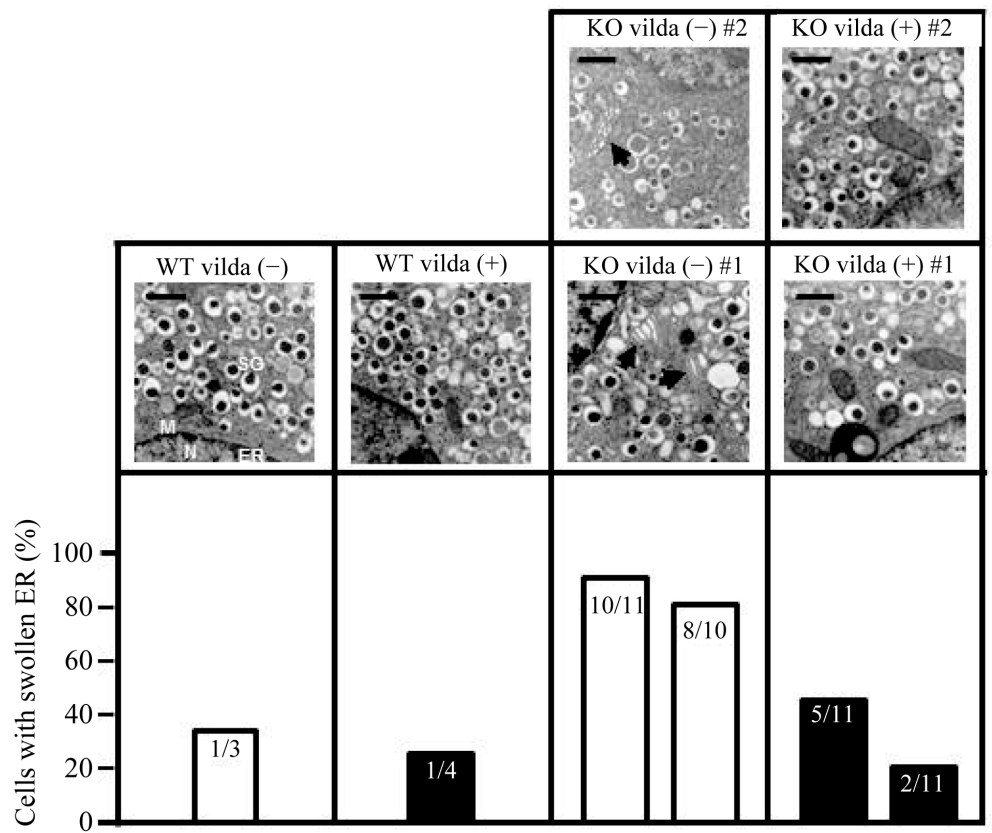

(a)

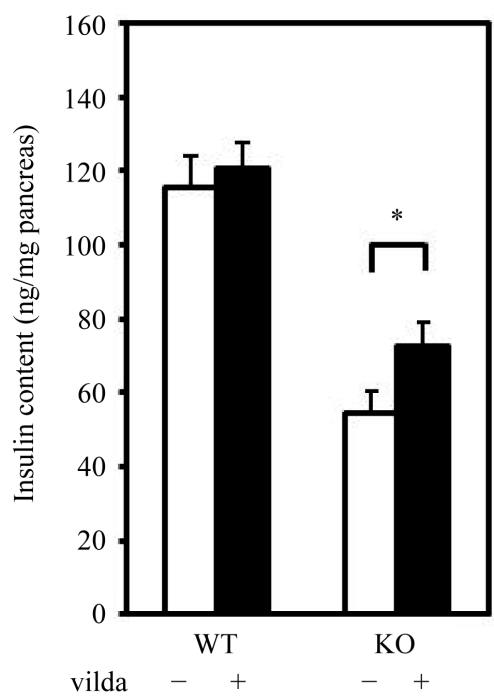

(b)

Figure 2. (a) Ultrastrucual analysis was performed on pancreatic sections from vehicle-treated WT mice $(\mathrm{n}=1)$, vildagliptin-treated WT mice $(n=1)$, vehicle-treated $W f s 1^{-/-}$mice $(\mathrm{KO}, \mathrm{n}=2)$, and vildagliptin-treated $W f s 1^{-/-}$mice $(\mathrm{n}=2)$. The bar graph represents the percentage of $\beta$-cells with swollen ER of each mouse, and counted numbers of $\beta$-cells were shown in the bars. Representative images of electron micrographs are shown. N: nucleus, SG: secretory granule, M: mitochondria, ER: endoplasmic reticulum, scale bars: $500 \mathrm{~nm}$. (b) Insulin content extracted from whole pancreata. Data are presented as means \pm SE, $n=7$ - 9 mice. ${ }^{*} \mathrm{p}<0.05$.

as compared with that of WT mice (Figure 2(b)), consistent with our previous report [6]. Vildagliptin treatment increased pancreatic insulin content to $133 \pm 12 \%(\mathrm{p}<0.05)$ in $W f s 1^{-/-}$mice, while vildagliptin unaltered the 
parameter in WT mice (Figure 2(b)).

\subsection{Four-Week Treatment with Vildagliptin Improved Glucose Tolerance in Wfs1-/- Mice}

In order to determine effects on glucose tolerance of long-term DPP-4 inhibition, we planned to conduct an intraperitoneal glucose tolerance test (IPGTT). IPGTT was chosen because unaltered glucose tolerance during IPGTT in the GLP-1 and GIP receptors double knockout mice indicated that acute incretin activation was not directly involved when glucose was administered intraperitoneally [16], allowing separation of long-term effects on glucose tolerance. Nonetheless, before conducting IPGTT, OGTT was performed after 3-week treatment with vildagliptin. Overnight-fasted mice were challenged with glucose $24 \mathrm{~h}$ after the last administration of vildagliptin. Blood glucose excursions were lower in WT mice treated with vildagliptin for 3 weeks than in vehicle-treated controls (Figure 3(a)). As reported previously [6], $W f s 1^{-/-}$mice started to develop impaired glucose tolerance at 8 weeks of age, and their glycemic levels after oral glucose challenge were reduced by vildagliptin treatment

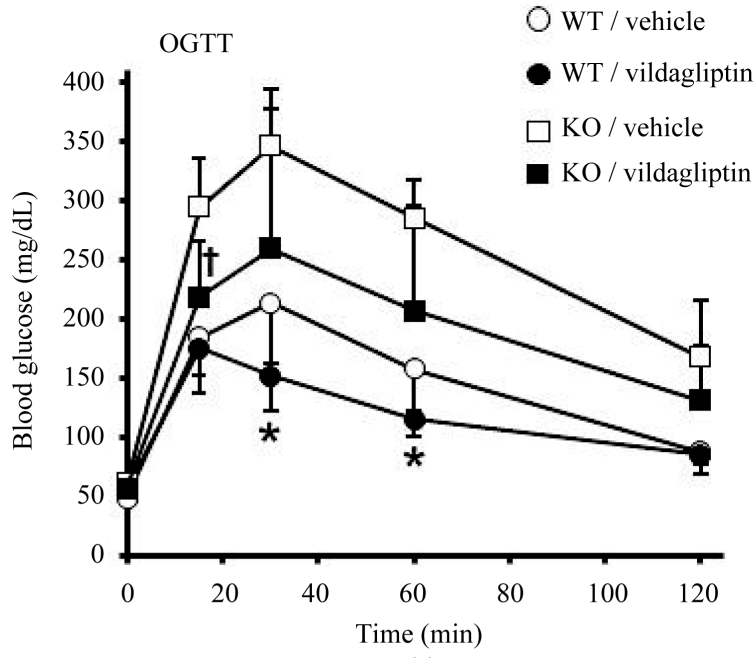

(a)

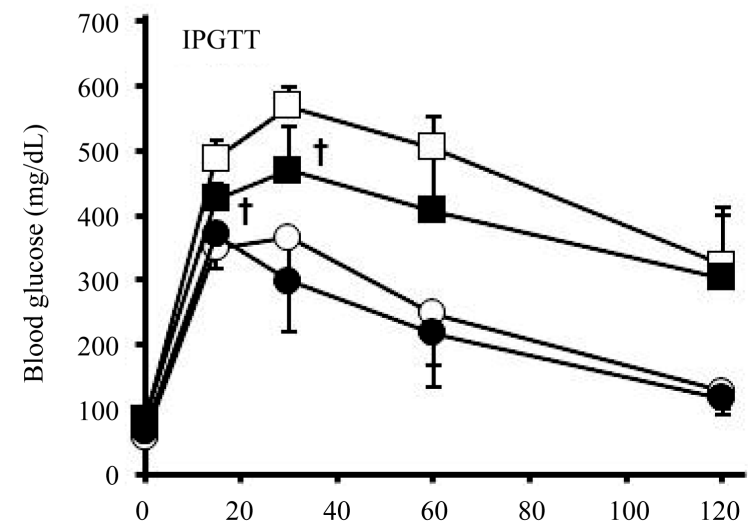

(c)

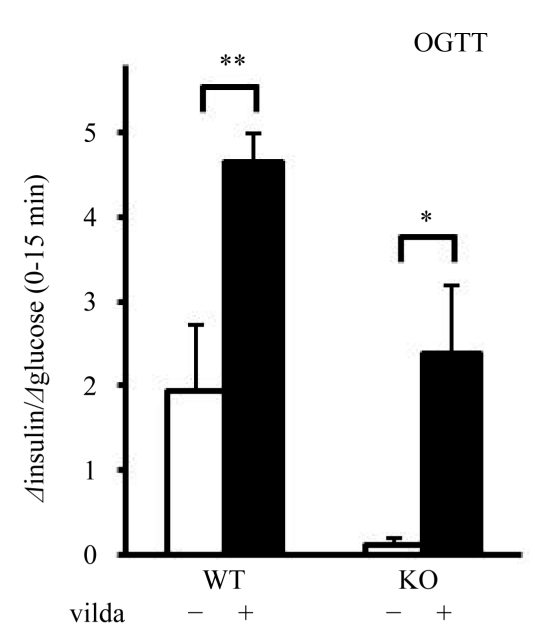

(b)

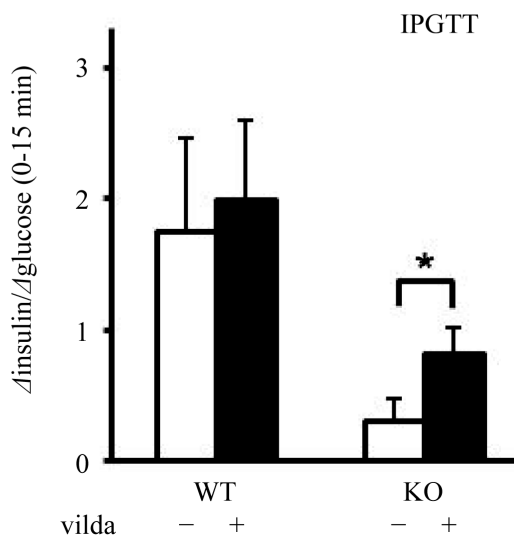

(d)

Figure 3. (a) (b) Oral glucose tolerance tests ( $2 \mathrm{~g} / \mathrm{kg}$ body weight) were performed in WT and $W f s 1^{-/-}$mice (KO) at 8 weeks of age with or without 4-week vildagliptin treatment. (a) Blood glucose levels were lower in vildagliptintreated mice. ${ }^{*} \mathrm{p}<0.05$ between vildagliptin- and vehicle-treated WT mice. ${ }^{\dagger} \mathrm{p}<0.05$ between vildagliptin- and vehicle-treated $W f s 1^{-/}$mice. (b) Insulin secretory response was calculated by dividing changes of plasma insulin levels during 15 min by changes of blood glucose. ${ }^{*} \mathrm{p}<0.05$. ${ }^{* *} \mathrm{p}<0.01$. (c) (d) Intraperitoneal glucose tolerance tests $(2$ $\mathrm{g} / \mathrm{kg}$ body weight) were performed in WT and $W f s 1^{-1-}$ mice at 9 weeks of age with or without 4-week vildagliptin treatment. (c) Blood glucose levels were lower in vildagliptin-treated $W f s 1^{-1-}$ mice. ${ }^{\dagger} \mathrm{p}<0.05$ between vildagliptinand vehicle-treated $W f s 1^{-/-}$mice. (d) Insulin secretory response was calculated as in (b). ${ }^{*} \mathrm{p}<0.05$. Data are presented as means $\pm \mathrm{SE}, \mathrm{n}=5-7$ mice. 
(Figure 3(a)). Plasma insulin over glucose ratios determined 15 min after glucose load were higher in vildagliptin- than in vehicle-treated mice in both strains (Figure 3(b)).

$\mathrm{WT}$ and $W f s 1^{-/-}$mice at 9 weeks of age were then subjected to an IPGTT $24 \mathrm{~h}$ after the last administration of vildagliptin. There was no difference in glucose excursion (Figure 3(c)) and insulin secretion (Figure 3(d)) between vehicle- and vildagliptin-treated WT mice. Interestingly, vildagliptin-treated WFS1-deficient mice showed improved glucose tolerance as compared with vehicle-treated $W f s 1^{-/-}$mice (Figure 3(c)), which was accompanied with improved glucose responsiveness in insulin secretion (Figure 3(d)). There seems to be no effects on whole body insulin sensitivity of vildagliptin treatment, since insulin $(0.75 \mathrm{U} / \mathrm{kg})$ tolerance test showed no differences in glucose lowering among four groups of mice at 9 weeks of age (data not shown).

\subsection{The $\beta$-Cell Protective Effect of Vildagliptin Was Partly Blocked by Exendin (9 - 39)}

The effects of DPP-4 inhibitors on glucose homeostasis are complicated, since a number of physiologically active substances including various hormones and cytokines, are regulated by DPP-4. In order to examine that the effects obtained by long-term treatment with vildagliptin were attributed to enhanced action of GLP-1, we conducted experiments using a GLP-1 receptor antagonist exendin (9 - 39). Exendin (9 - 39) (30 nmol/kg body weight) was intraperitoneally administrated twice a day in combination with vildagliptin or vehicle to $\mathrm{Wfs} 1^{-/}$ mice for 4 weeks.

Pancreatic insulin content of these mice was analyzed. Similar to data shown in Figure 2(b), insulin content of vildagliptin-treated $W f s 1^{-/}$mouse pancreases was increased to $128 \pm 10 \%(\mathrm{p}<0.05)$ as compared with that of vehicle-treated ones (Figure 4(a)). However, exendin (9 - 39) treatment blocked vildagliptin-induced increases in pancreatic insulin content (Figure 4(a)). These results demonstrate that protective effects of vildagliptin on $W f s 1^{-/-}$mice were, at least partly, through active GLP-1.

We also analyzed glucose tolerance of these mice after 4-week treatment. The overnight-fasted mice at 9 weeks of age were subjected to an IPGTT $24 \mathrm{~h}$ after the last administration of the drugs. Although blood glucose levels were significantly lower in vildagliptin- than in vehicle-treated mice, there were no differences between vildagliptin plus exendin $\left(9\right.$ - 39)-treated and vehicle-treated $W f s 1^{-1-}$ mice (Figure 4(b)). We also observed that vildagliptin-augmented plasma insulin over glucose ratios were reduced by exendin (9 - 39), although the difference between vilidagliptin-induced increases in the ratios was not statistically significant between with and without exendin (9 - 39) co-treatment (Figure 4(c)).

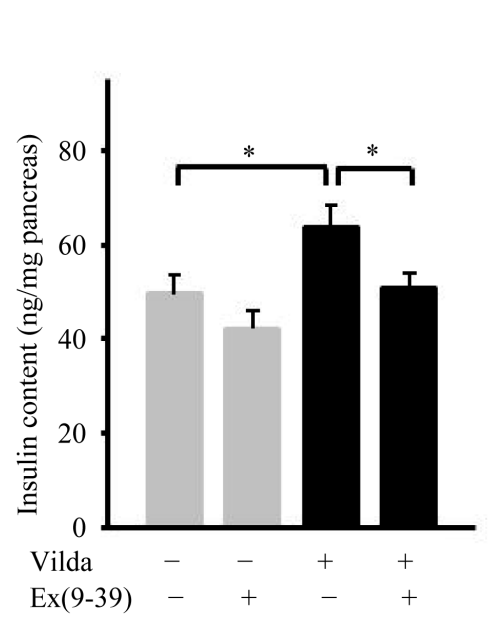

(a)

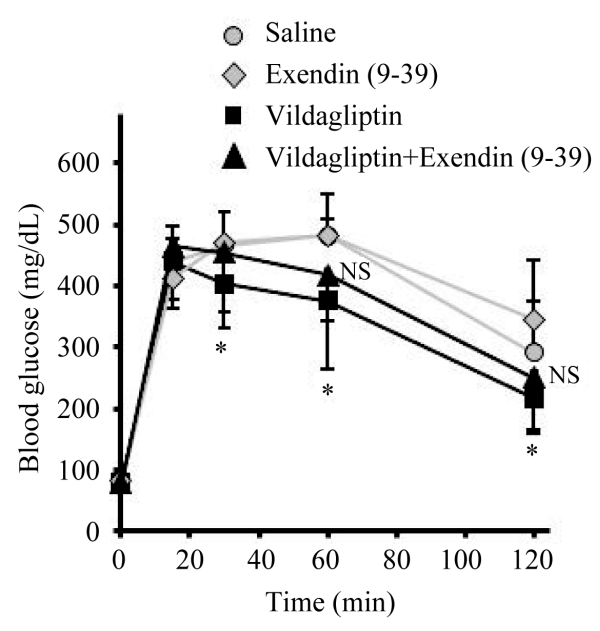

(b)

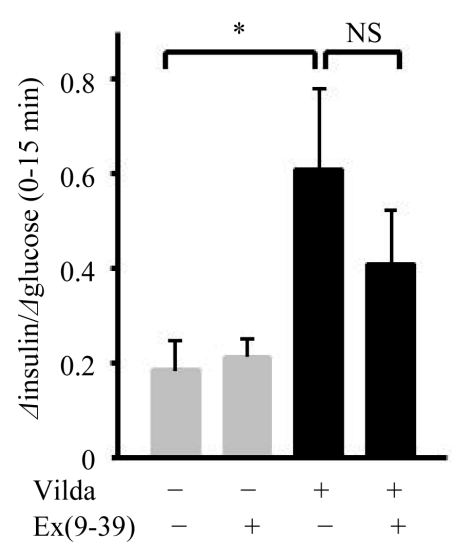

(c)

Figure 4. (a) Insulin content extracted from whole pancreas of $W f s 1^{-/-}$mice treated with vildagliptin and/or exendin (9 - 39) at age of 9 weeks. ${ }^{*} \mathrm{p}<0.05$. Data are presented as means $\pm \mathrm{SE}, \mathrm{n}=7-12$ mice. (b), (c) Intraperitoneal glucose tolerance tests were performed at 9 weeks of age after 4 -week continuous treatment of $W f s 1^{-/}$mice with vildagliptin and/or exendin (9 39). (b) Blood glucose levels are presented. ${ }^{*} \mathrm{p}<0.05$ between vildagliptin- and vehicle-treated $W f s 1^{-/-}$mice. NS, not significant between mice treated with vildagliptin plus exendin $\left(9\right.$ - 39) and vehicle-treated $W f s 1^{-/}$mice. (c) Insulin secretory response was calculated by dividing changes of plasma insulin levels during $15 \mathrm{~min}$ by changes of blood glucose. ${ }^{*} \mathrm{p}<0.05$. 


\section{Discussion}

The present study showed that DPP-4 inhibition ameliorates $\beta$-cell failure and improves glucose tolerance in wolframin-deficient mice. Our data might be suggestive for the treatment strategy of diabetes in Wolfram syndrome patients.

We observed that vildagliptin treatment reduced $\beta$-cell numbers with swollen ER, a typical phenotype of ER stressed cells. The result suggested that vildagliptin reduced ER stress per se or made $\beta$-cells resistant to ER stress, leading to improvement of cellular homeostasis of WFS1-deficienct $\beta$-cells. ER stress conditions could be analyzed by changes in ER stress sensor or marker protein expressions. Previous studies have showed that expressions of ER stress markers, ATF4 and GRP78, were increased by GLP-1-receptor agonist, exendin-4 [17] [18]. Increased expression of ATF4 and GRP78 is also observed in cells undergoing apoptosis caused by ERstress inducers. Therefore, when one observed ATF4 and/or GPR78 induction in cells, it is difficult for one to judge or interpret whether cells are undergoing apoptosis or recovering from ER stress conditions. This is the reason why we evaluated ER stress conditions morphologically, as in a report by Scheuner et al. [15].

Theoretically, since effects of DPP-4 inhibitors and of incretin hormones are diverse, it was possible that improvement of glucose tolerance in $W f s 1^{-1-}$ mice was due to vildagliptin-activated incretin actions outside $\beta$-cells. Nonetheless, we believe that the major contributor for improved glucose tolerance was restoration of $\beta$-cell function, because the primary cause of diabetes is $\beta$-cell dysfunction in $W f s 1^{-/}$mice. In addition, an interesting observation in our study was that glucose tolerance was improved when glucose was challenged through intraperitoneally in $W f s 1^{-/-}$mice. Since incretin system might not be involved in glucose tolerance after intraperitoneal glucose challenge, improved glucose responsiveness of insulin secretion from $W f s 1^{-/}$mice treated with vildagliptin indicated restored $\beta$-cell function per se, which might include enhanced responsiveness of individual $\beta$-cells and/or increased $\beta$-cell mass. Increases in pancreatic insulin content in $W f s 1^{-/}$mice treated with vildagliptin (Figure 2(b)) supported the latter mechanism.

In rodent diabetic models, GLP-1 receptor agonists and DPP-4 inhibitors have been reported to have beneficial effects on $\beta$-cell mass through stimulating proliferation, preventing cell death, or promoting neogenesis [14] [19]-[22]. An interesting observation has been reported in $\beta$-cell specific C/EBPB transgenic mice suffering from $\beta$-cell loss caused by increased ER stress [23]. Importantly, vildagliptin treatment has been shown to ameliorate ER stress through C/EBPB degradation in the mutant mouse $\beta$-cells. Since function of WFS1 protein remains elusive, mechanisms by which vildagliptin protects $\beta$-cell from ER stress in $W f s 1^{-/}$mice is unknown and should be solved in the near future.

The present data suggest incretin-based therapy as a potential therapeutic option for Wolfram syndrome. Since recent studies have revealed neuroprotective effects of GLP-1 [24], it will be quite intriguing to see whether symptoms outside $\beta$-cells of Wolfram syndrome, such as diabetes insipidus and optic atrophy, can be suppressed by incretin-based drugs. Very recently, wolframin-deficient $\beta$-cells have been generated from human induced pluripotent stem (iPS) cells derived from subjects with Wolfram syndrome [25]. Wolfram $\beta$-cells showed increased levels of ER stress markers and reduced insulin secretion. Remarkably, a chemical chaperon has been reported to upregulate insulin secretion. Another report generated neural progenitor cells from iPS cells of Wolfram syndrome patients and a calcium-dependent protease has been shown to prevent cell death in these mutants [26]. These studies contribute to our understanding and development of therapeutic strategies not only for Wolfram syndrome but also for type 2 diabetes mellitus, since WFS1 abnormalities are linked to common forms of type 2 diabetes mellitus.

\section{Acknowledgements}

We are grateful to C. Suzuki and M. Kato for their expert technical assistance. This research was supported by Grants-in-Aid for Scientific Research (21591147 and 22790842) to H.I. and S.Y., respectively, from the Ministry of Education, Science, Sports and Culture of Japan.

\section{Conflict of Interest}

HI has received lecture fees from Asteras, Astrazeneca, Boehringer Ingelheim, Daiichi Sankyo Inc., Eli Lilly and Company, Kowa Pharmaceutical Co., MSD, Novartis Pharmaceuticals, Novo Nordisk Pharma, Ono Pharmaceutical Co., Mitsubishi Tanabe Pharma, and Sanofi, and research funds from Asteras, Boehringer Ingelheim, 
Daiichi Sankyo Inc., Eli Lilly, Kowa Pharmaceutical Co., MSD, Mitsubishi Tanabe Pharma, Novartis Pharmaceuticals, Novo Nordisk Pharma, Sanofi, and Takeda Pharmaceutical Co.

\section{References}

[1] Wolfram, D.J. and Wagener, H.P. (1938) Diabetes Mellitus and Simple Optic Atrophy among Siblings: Report on Four Cases. Mayo Clinic Proceedings, 13, 715-718.

[2] Inoue, H., Tanizawa, Y., Wasson, J., Behn, P., Kalidas, K., Bernal-Mizrachi, E., et al. (1998) A Gene Encoding a Transmembrane Protein Is Mutated in Patients with Diabetes Mellitus and Optic Atrophy (Wolfram Syndrome). Nature Genetics, 20, 143-148. http://dx.doi.org/10.1038/2441

[3] Strom, T.M., Hortnagel, K., Hofmann, S., Gekeler, F., Scharfe, C., Rabl, W., et al. (1998) Diabetes Insipidus, Diabetes Mellitus, Optic Atrophy and Deafness (DIDMOAD) Caused by Mutations in a Novel Gene (Wolframin) Coding for a Predicted Transmembrane Protein. Human Molecular Genetics, 7, 2021-2028. http://dx.doi.org/10.1093/hmg/7.13.2021

[4] Sandhu, M.S., Weedon, M.N., Fawcett, K.A., Wasson, J., Debenham, S.L., Daly, A., et al. (2007) Common Variants in WFS1 Confer Risk of Type 2 Diabetes. Nature Genetics, 39, 951-953. http://dx.doi.org/10.1038/ng2067

[5] Franks, P.W., Rolandsson, O., Debenham, S.L., Fawcett, K.A., Payne, F., Dina, C., et al. (2008) Replication of the Association between Variants in WFS1 and Risk of Type 2 Diabetes in European Populations. Diabetologia, 51, 458463. http://dx.doi.org/10.1007/s00125-007-0887-6

[6] Ishihara, H., Takeda, S., Tamura, A., Takahashi, R., Yamaguchi, S., Takei, D., et al. (2004) Disruption of the WFS1 Gene in Mice Causes Progressive Beta-Cell Loss and Impaired Stimulus-Secretion Coupling in Insulin Secretion. Human Molecular Genetics, 13, 1159-1170. http://dx.doi.org/10.1093/hmg/ddh125

[7] Yamada, T., Ishihara, H., Tamura, A., Takahashi, R., Yamaguchi, S., Takei, D., et al. (2006) WFS1-Deficiency Increases Endoplasmic Reticulum Stress, Impairs Cell Cycle Progression and Triggers the Apoptotic Pathway Specifically in Pancreatic Beta-Cells. Human Molecular Genetics, 15, 1600-1609. http://dx.doi.org/10.1093/hmg/ddl081

[8] Eizirik, D.L., Cardozo, A.K. and Cnop, M. (2008) The Role for Endoplasmic Reticulum Stress in Diabetes Mellitus. Endocrine Reviews, 29, 42-61. http://dx.doi.org/10.1210/er.2007-0015

[9] Laybutt, D.R., Preston, A.M., Akerfeldt, M.C., Kench, J.G., Busch, A.K., Biankin, A.V., et al. (2007) Endoplasmic Rectium Stress Contributes to Beta Cell Apoptosis in Type 2 Diabetes. Diabetologia, 50, 752-763. http://dx.doi.org/10.1007/s00125-006-0590-z

[10] Buton,J., Foisy, S., Rhodes, C.J., Carpenter, L., Biden, T.J. and Prentki, M. (2001) Protein Kinase Czeta Activation Mediates Glucagon-Like Peptide-1-Induced Pancreatic Beta-Cell Proliferation. Diabetes, 50, 2237-2243. http://dx.doi.org/10.2337/diabetes.50.10.2237

[11] Kitamura, T., Nakae, J., Kitamura, Y., Kido, Y., Biggs 3rd, W.H., Wright, C.V., et al. (2001). The Forkhead Transcription Factor Foxo1 Links Insulin Signaling to Pdx1 Regulation of Pancreatic Beta Cell Growth. Journal Clinical Investigation, 110, 1839-1847. http://dx.doi.org/10.1172/JCI200216857

[12] Hui, H., Nourparvar, A., Zhao, X. and Perfetti, R. (2003) Glucagon-Like Peptide-1 Inhibits Apoptosis of InsulinSecreting Cells via a Cyclic 5'-Adenosine Monophosphate-Dependent Protein Kinase A- and a Phosphatidylinositol 3-Kinase-Dependent Pathway. Endocrinology, 144, 1444-1455. http://dx.doi.org/10.1210/en.2002-220897

[13] Kim, S.J., Winter, K., Nian, C., Tsuneoka, M., Koda, Y. and McIntosh, C.H. (2005) GIP Stimulation of Pancreatic BetaCell Survival Is Dependent upon Phosphatidylinositol 3-Kinase (PI3-K)/Protein Kinase B (PKB) Signaling, Inactivation of the Forkhead Transcription Factor Foxo1 and Downregulation of Bax Expression. Journal of Biological Chemistry, 280, 22297-22307. http://dx.doi.org/10.1074/jbc.M500540200

[14] Shimizu, S., Hosooka, T., Matsuda, T., Asahara, S., Koyanagi-Kimura, M., Kanno, A., et al. (2012) DPP-4 Inhibitor Viildagliptin Preserved $\beta$-Cell Mass through Amelioration of Endoplasmic Reticulum Stress in C/EBPB Transgenic Mice. Journal of Molecular Endocrinology, 49, 125-135. http://dx.doi.org/10.1530/JME-12-0039

[15] Scheuner, D., Vander Mierde, D., Song, B., Flamez, D., Creemers, J.W., Tsukamoto, K., et al. (2005) Control of mRNA Translation Preserves Endoplasmic Reticulum Function in Beta Cells and Maintains Glucose Homeostasis. Nature Medicine, 11, 757-764. http://dx.doi.org/10.1038/nm1259

[16] Preitner, F., Ibberson, M., Franklin, I., Binnert, C., Pende, M., Gjinovci, A., et al. (2004) Gluco-Incretins Control Insulin Secretion at Multiple Levels as Revealed in Mice Lacking GLP-1 and GIP Receptors. Journal Clinical Investigation, 113, 635-645. http://dx.doi.org/10.1172/JCI200420518

[17] Yusta, B., Baggio, L.L., Estall, J.L., Koehler, J.A., Holland, D.P., Li, H., et al. (2006) GLP-1 Receptor Activation Improves Beta Cell Function and Survival Following Induction of Endoplasmic Reticulum Stress. Cell Metabolism, 4, 391-406. http://dx.doi.org/10.1016/j.cmet.2006.10.001 
[18] Cunha, D.A., Ladrière, L., Ortis, F., Igoillo-Esteve, M., Gurzov, E.N., Lupi, R., et al. (2006) Glucagon-Like Peptide-1 Agonists Protect Pancreatic Beta-Cells from Lipotoxic Endoplasmic Reticulum Stress through Upregulation of BiP and JunB. Diabetes, 58, 2851-2862. http://dx.doi.org/10.2337/db09-0685

[19] Mu, J., Petrov, A., Eiermann, G.J., Woods, J., Zhou, Y.P., Li, Z., et al. (2009) Inhibition of DPP-4 with Sitagliptin Improves Glycemic Control and Restores Islet Cell Mass and Function in a Rodent Model of Type 2 Diabetes. European Journal of Pharmacology, 623, 148-154. http://dx.doi.org/10.1016/j.ejphar.2009.09.027

[20] Duttaroy, A., Voelker, F., Merriam, K., Zhang, X., Ren, X., Subramanian, K., et al. (2011) The DPP-4 Inhibitor Vildagliptin Increases Pancreatic Beta Cell Mass in Neonatal Rats. European Journal of Pharmacology, 650,703-707. http://dx.doi.org/10.1016/j.ejphar.2010.10.062

[21] Xu, G., Stoffers, D.A., Habener, J.F. and Bonner-Weir, S. (1999) Exendin-4 Stimulates Both Beta-Cell Replication and Neogenesis, Resulting in Increased Beta-Cell Mass and Improved Glucose Tolerance in Diabetic Rats. Diabetes, 48, 2270-2276. http://dx.doi.org/10.2337/diabetes.48.12.2270

[22] Zhang, X., Wang, Z., Huang, Y. and Wang, J. (2011) Effects of Chronic Administration of Alogliptin on the Development of Diabetes and $\beta$-Cell Function in High Fat Diet/Streptozotocin Diabetic Mice. Diabetes Obesity and Metabolism, 13, 337-347. http://dx.doi.org/10.1111/j.1463-1326.2010.01354.x

[23] Shinobu Shimizu, S., Hosooka, T., Matsuda, T., Asahara, S., Koyanagi-Kimura, M., Kanno, A., et al. (2012) DPP4 Inhibitor Vildagliptin Preserves $\beta$-Cell Mass through Amelioration of Endoplasmic Reticulum Stress in C/EBPB Transgenic Mice. Journal of Molecular Endocrinology, 49, 125-135. http://dx.doi.org/10.1530/JME-12-0039

[24] Salcedo, I., Tweedie, D., Li, Y. and Greig, N.H. (2012) Neuroprotective and Neurotrophic Actions of Glucagon-Like Peptide-1: An Emerging Opportunity to Treat Neurodegenerative and Cerebrovascular Disorders. British Journal of Pharmacology, 166, 1586-1599. http://dx.doi.org/10.1111/j.1476-5381.2012.01971.X

[25] Shang, L., Hua, H., Foo, K., Martinez, H., Watanabe, K., Zimmer, M., et al. (2014) $\beta$-Cell Dysfunction Due to Increased ER Stress in a Stem Cell Model of Wolfram Syndrome. Diabetes, 63, 923-933. http://dx.doi.org/10.2337/db13-0717

[26] Lu, S., Kanekura, K., Hara, T., Mahadevan, J., Spears, L.D., Oslowski, C.M., et al. (2014) A Calcium-Dependent Protease as a Potential Therapeutic Target for Wolfram Syndrome. Proceedings of National Academy of Sciences of the United States of America, 111, E5292-E5301. http://dx.doi.org/10.1073/pnas.1421055111 